\title{
UMA NOVA ESPÉCIE DO GÊNERO BACCHARIS LINNAEUS - SEÇÃO CUNEIFOLIAE - PARA O SUL DO BRASIL (ASTERACEAE - ASTEREAE) ${ }^{1}$
}

\author{
ANABELA SILVEIRA DE OLIVEIRA² JOSÉ NEWTON CARDOSO MARCHIORI ${ }^{3}$
}

\section{RESUMO}

No presente trabalho é descrita e ilustrada uma nova espécie da flora sul-brasileira: Baccharis deblei An. S. de Oliveira \& Marchiori. A espécie tem sua distribuição geográfica representada em mapa e é diferenciada de duas espécies afins, Baccharis gilliesii A. Gray e Baccharis trineura Soria \& Zardini, mediante chave dicotômica.

Palavras-chave: Baccharis, seção Cuneifoliae, Astereae, Asteraceae, espécie nova.

\section{ABSTRACT}

Baccharis deblei An. S. de Oliveira \& Marchiori, a new species from southern Brazil, is described and illustrated. The geographical distribution is represented in map and the species is separated from Baccharis gilliesii A. Gray and B. trineura Soria \& Zardini by a dichotomous key.

Key words: Baccharis, section Cuneifoliae, Astereae, Asteraceae, new species.

\section{INTRODUÇÃO}

Na revisão do gênero Baccharis L. para o sul do Brasil foi reconhecida uma nova espécie, denominada Baccharis deblei An. S. de Oliveira \& Marchiori. Bastante rara, sua área de distribuição restringe-se aos Aparados da Serra Geral, nos municípios de São José dos Ausentes (Serra da Rocinha) e Cambará do Sul (Serra da Pedra), no Estado do Rio Grande do Sul, bem como em Bom Jardim da Serra (Serra do Rio do Rastro, Serra do Oratório), Bom Retiro (Campo dos Padres) e Urubici (Morro da Igreja), no Estado de Santa Catarina (Figura 2).

\section{DESCRIÇÃO}

\section{Baccharis deblei An. S. de Oliveira \& Marchiori, sp. nov. ${ }^{4}$}

Suffrutex glandulosus, $50-70 \mathrm{~cm}$ altus; caulibus erectis, usque apice foliosum. Folia 3-10 mm longa, 2-4 mm lata, elliptica, alterna (internodiis 1,5-3 mm), sessilia, glabra, uninervata, integra, apice et base obtusa. Capitula sessilia, solitaria, in apice ramulorum. Capitula plantarum feminearum involucrum campanulatum, 9-10 mm altum, 6-8 $\mathrm{mm}$ crassum; bracteis involucralibus 4-5-seriatis: externis ovatis, obtusis, 2-4 mm longis, $2 \mathrm{~mm}$ latis; mediis lanceolatis, subobtusis, $5-6 \mathrm{~mm}$ longis, $2 \mathrm{~mm}$ latis; interioribus oblanceolatis, acutis, $8-9 \mathrm{~mm}$ longis, $1-1,5$ $\mathrm{mm}$ latis. Flores feminei 110-130; corolla $6 \mathrm{~mm}$ longa; stylo 8,5 mm longo. Pappus rufescentibus, $8,5 \mathrm{~mm}$ longus. Achaenia 10-costata, 1,5-2 mm longa. Capitula plantarum mascularum involucrum campanulatum, 7-9 mm altum, 8-9 mm crassum; bracteis involucralibus 4-seriatis; externis ovatis, obtusis ad trunculatis, 3-4 mm longis, 2 mm latis; mediis, oblongis, obtusis, 4-5 mm longis, 1,5 mm latis; internis oblanceolatis, acutis, 6-7 mm longis, 1 $\mathrm{mm}$ latis. Flores mascula 50-60; corolla $8,3 \mathrm{~mm}$ longa, apice 5-secta, revoluta. Pappus rufescentibus, $6 \mathrm{~mm}$ longus. A Baccharis trineura Soria \& Zardini, cui affinis, folia minor, elliptica, uninervata, integra, differt. A Baccharis gilliesii A. Gray, cui proxima, folia elliptica, integra et capitula magna, differt.

TIPO - BRASIL, Santa Catarina, Bom Jardim da Serra, Serra do Rio do Rastro, em turfeira, subarbusto ramoso de $60 \mathrm{~cm}$, flores brancas, L. P. Deble, An. S. de Oliveira \& Marchiori, 5.XI.2004. Holotypus MBM, Isotypi ICN, PACA, HDCF, SI.

\footnotetext{
Artigo financiado pelo CNPq. Original recebido em 03/01/2005 e aceito para publicação em 07/03/2005.

2 Bióloga, Msc. Doutoranda do Programa de Pós-graduação em Engenharia Florestal, Centro de Ciências Rurais, Universidade Federal de Santa Maria, CEP 97105-900, Santa Maria (RS). anabela.biol@mail.ufsm.br

3 Engenheiro Florestal, Dr., Professor Titular do Departamento de Ciências Florestais, Centro de Ciências Rurais, Universidade de Santa Maria, CEP 97105-900, Santa Maria (RS). balduinia@mail.ufsm.br

4 O epíteto específico é uma homenagem ao botânico Leonardo Paz Deble, pela coleta do material-tipo.
} 
Subarbusto ramoso, glanduloso, de $50-70 \mathrm{~cm}$ de altura; ramos eretos, folhosos até o ápice (Figura 1a). Folhas elípticas, de 3-10 mm de comprimento por $2-4 \mathrm{~mm}$ de largura, alternas (entrenós de 1,5-3 mm), sésseis, glabras, uninérvias, de margem inteira, obtusas no ápice e base (Figura a'). Capítulos sésseis, isolados no ápice dos ramos, rodeados por um falso invólucro de pequenas folhas (Figura 1a). Capítulos femininos campanulados, com invólucro de 9-10 $\mathrm{mm}$ de altura por 6-8 $\mathrm{mm}$ de diâmetro (Figura 1b). Brácteas involucrais hialinas na margem e enegrecidas no ápice, dispostas em 4-5 séries; as externas, ovadas e de ápice obtuso, com 2-4 mm de comprimento por $2 \mathrm{~mm}$ de largura (Figura 1b); as medianas, lanceoladas e levemente agudas no ápice, de 5-6 mm de comprimento por $2 \mathrm{~mm}$ de largura (Figura 1b); as internas, oblanceoladas e agudas no ápice, de $8-9 \mathrm{~mm}$ de comprimento por 1-1,5 mm de largura (Figura 1b). Flores femininas, 110-130, com corola de $6 \mathrm{~mm}$ de comprimento e bordo truncado (Figura 1c). Estigma exserto ao tubo da corola, bífido, com cerca de $8,5 \mathrm{~mm}$ de comprimento (Figura 1c). Pápus com cerdas de 8,5 $\mathrm{mm}$ de comprimento (Figura 1c). Aquênios 10costados, cilíndricos e de contorno elíptico, com 1,5-2 mm de comprimento (Figura 1f). Capítulos masculinos campanulados, com invólucro de 7-9 $\mathrm{mm}$ de altura por 8-9 $\mathrm{mm}$ de diâmetro (Figura 1d). Brácteas involucrais dispostas em 4 séries; as externas, ovadas e de ápice obtuso a truncado, com 3-4 mm de comprimento por 2 $\mathrm{mm}$ de largura (Figura 1d); as medianas, oblongas e obtusas no ápice, com 4-5 mm de comprimento por 1,5 mm de largura (Figura 1d); as internas, oblanceoladas e agudas no ápice, com 6-7 $\mathrm{mm}$ de comprimento por $1 \mathrm{~mm}$ de largura (Figura 1d). Flores masculinas, cerca de 50-60, com corola de $8,3 \mathrm{~mm}$ de comprimento, e ápice 5-secto, revoluto (Figura 1e); rudimento do estigma de 7,5-8 $\mathrm{mm}$ de comprimento, com ramos longos e aderidos entre si (Figura 1e). Pápus com cerdas onduladas, de $6 \mathrm{~mm}$ de comprimento (Figura 1e).
Habitat \& Fenologia: Espécie rara, restrita a campos turfosos dos Aparados da Serra Geral, em altitudes superiores a $900 \mathrm{~m}$, nos estados de Santa Catarina e Rio Grande do Sul. Coletada com flores e frutos, de novembro a março.

Comentários: Baccharis deblei apresenta afinidade com Baccharis gilliesii A. Gray, da Argentina, da qual se separa pelo hábito, pela forma das folhas e pelos capítulos distintamente maiores. De Baccharis trineura Soria \& Zardini (= B. triplinervia (Less.) Baker [nom. illeg.]), difere principalmente pelo tamanho e forma das folhas. As três espécies podem ser distinguidas pela seguinte chave dicotômica:

1a.Folhas trinérvias, oblongas e serradas na metade superior, com 20-30 mm de comprimento por $10-15 \mathrm{~mm}$ de largura.

..Baccharis trineura Soria \& Zardini

$1 \mathrm{~b}$.Folhas uninérvias, lineares, linearespatuladas ou elípticas, de margem inteira ou com 1-6 dentes.

2a.Subarbusto de $10-30 \mathrm{~cm}$ de altura. Folhas lineares a linear-espatuladas, de 5-20 mm de comprimento por 1-3 mm de largura, com margens íntegras ou 1-6 dentes, e base atenuada. Capítulos femininos de 5-6 $\mathrm{mm}$ de altura por $4 \mathrm{~mm}$ de diâmetro. Capítulos masculinos de 4-5 mm de altura e diâmetro.

..Baccharis gilliesii A. Gray 2b. Subarbusto de 50-70 $\mathrm{cm}$ de altura. Folhas elípticas, de 3-10 mm de comprimento por 2-4 $\mathrm{mm}$ de largura, com margens inteiras e base obtusa. Capítulos femininos de $9-10 \mathrm{~mm}$ de altura por 6-8 mm de diâmetro. Capítulos masculinos de 7-9 mm de altura por 8-9 $\mathrm{mm}$ de diâmetro.

Baccharis deblei sp.nov.

Material examinado (paratypi): BRASIL: RIO GRANDE DO SUL: Cambará do Sul, Serra da Pedra p. Cambará, fl. fem., in sphagneto, B. Rambo, II.1948 (PACA 36.356). São José dos Ausentes, Serra da Rocinha, in paludoso, campo, 1.000 m, A. 


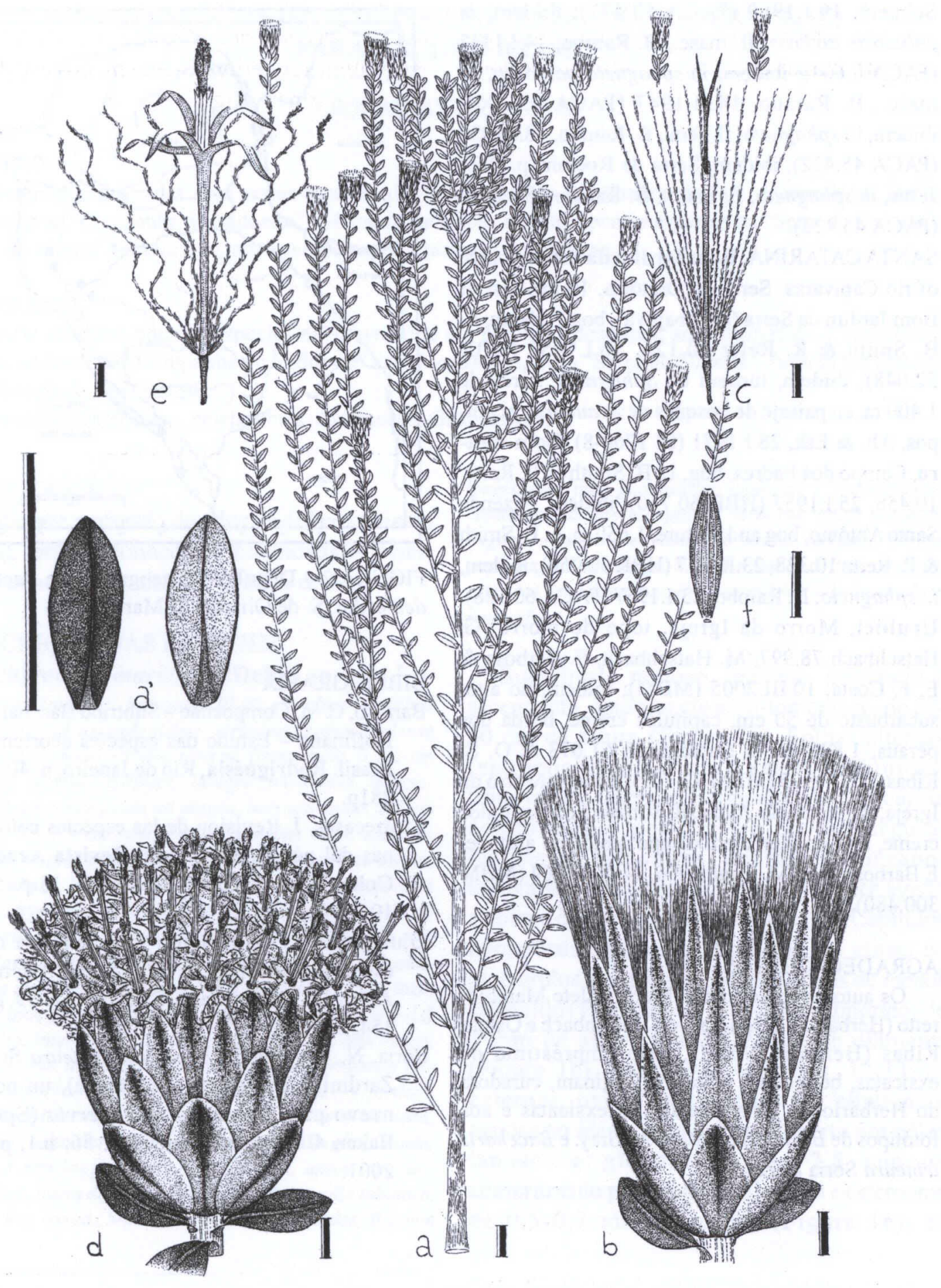

FIGURA 1- Ramo de Baccharis deblei (a). Folha (a'). Capítulo feminino (b). Flor feminina (c). Capítulo masculino (d). Flor masculina (e). Aquênio (f). Escala a, a' $=1 \mathrm{~cm} ; \mathrm{b}, \mathrm{c}, \mathrm{d}, \mathrm{e}, \mathrm{f}=1 \mathrm{~mm}$. 
Sehnem, 19.I.1959 (PACA 50.471); ibidem, in paludosis turfosis, fl. masc., B. Rambo, 14.I.1942 (PACA 8.604); ibidem, in sphagneto paludoso, fl. masc., B. Rambo, 14.II.1947 (PACA 35.195); ibidem, in sphagneto, fl. fem., B. Rambo, 18.I.1950 (PACA 45.432); ibidem, Serra da Rocinha p. Bom Jesus, in sphagneto, fl. masc., B. Rambo 18.I.1950 (PACA 45.428).

SANTA CATARINA: Bom Jardim da Serra, source of rio Capivaras, Serra do Oratório, $10 \mathrm{~km}$ east of Bom Jardim da Serra (Cambajuva), bog 1.200 m, L. B. Smith \& R. Reitz 10.126, 16.I.1957 (HBR 52.048); ibidem, turbera de Sphagnum, cerca de 1.400 m, en paisaje de bosques de Araucaria y campos, Ah. \& Esk, 28.I.1971 (SI 1760-8). Bom Retiro, Campo dos Padres, bog, L. B. Smith \& R. Reitz, 10.455, 25.I.1957 (HBR 50.710); ibidem, Fazenda Santo Antônio, bog and pasture, $1.650 \mathrm{~m}, \mathrm{~L}$. B. Smith \& R. Reitz 10.328, 23.I.1957 (HBR 52.056); ibidem, in sphagneto, B. Rambo, 23.I.1957 (PACA 60.128). Urubici, Morro da Igreja, topo do morro, G. Hatschbach 78.997, M. Hatschbach, E. Barbosa \& E. F. Costa, 10.III.2005 (MBM); ibidem, no alto, subarbusto de $50 \mathrm{~cm}$, capítulos creme, borda dos peraus, $1.800 \mathrm{~m}$, G. Hatschbach 61.673 \& O. S. Ribas, 16.II.1995 (MBM 72.709); ibidem, Morro da Igreja, salto do rio Avencal, subarbusto, capítulos creme, alto do morro em campo úmido de altitude, E Barbosa \& E. M. Cunha 996, 14.XII.2004 (MBM 300.480).

\section{AGRADECIMENTOS}

Os autores agradecem a Maria Salete Marchioretto (Herbário PACA) e a Gert Hatschbach e Osmar Ribas (Herbário MBM), pelo empréstimo de exsicatas, bem como a Norma Deginani, curadora do Herbário SI, pela consulta às exsicatas e aos fotótipos de Baccharis gilliesii A. Gray. e Baccharis trineura Soria \& Zardini.

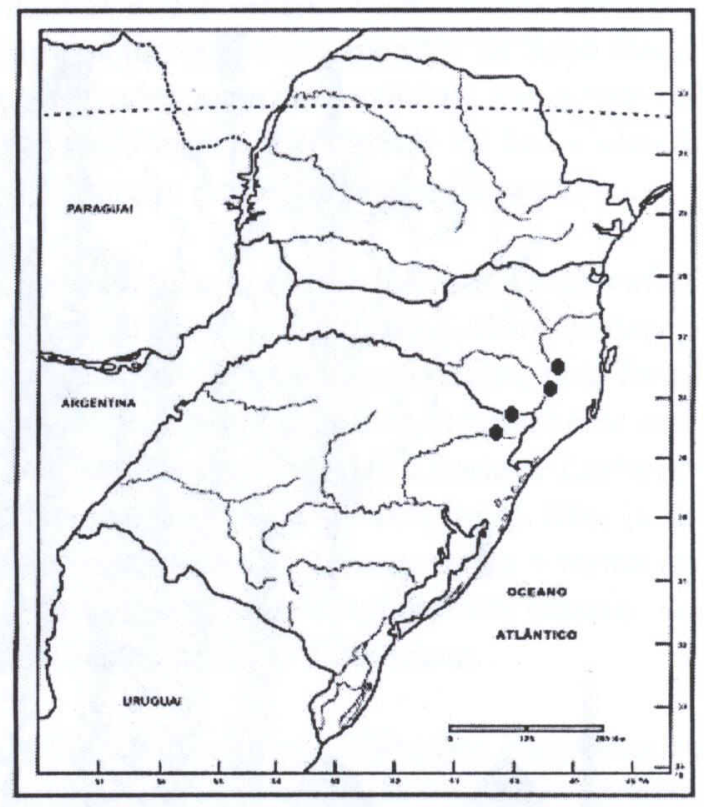

FIGURA 2 - Distribuição geográfica de Baccharis deblei An. S. de Oliveira \& Marchiori.

\section{BIBLIOGRAFIA}

Barroso, G. M. Compositae - Subtribo Baccharidinae Hoffmann - Estudo das espécies ocorrentes no Brasil. Rodriguésia, Rio de Janeiro, n. 40, 1976, 281p.

Cuatrecasas, J. Revisión de las espécies colombianas del género Baccharis. Revista Academia Colombiana Ciências Exatas, n. 13 p. 5-102. 1967.

Giuliano, D. Clasificación infragenérica de las especies argentinas de Baccharis (Asteraceae, Astereae). Darwiniana, San Isidro, n. 39, p.131154, 2001.

Soria, N., Zardini, E. Baccharis trineura Soria \& Zardini (Compositae - Astereae), un nombre nuevo para Baccharis triplinervia (Spreng.) Baker. Candollea, Genève, v. 56, n.1, p. 116, 2001. 